\title{
Hemothorax from external rupture of esophageal varices: An unusual fatal complication
}

\author{
Nigel H. Bramwell. BMed SCl, BM, BS, Roger W. Byard, BMed Scl, MB, BS, CCFP
}

\begin{abstract}
A case of sudden death caused by hemorrhage into the chest cavity from a linear tear of the external esophageal wall following yomiting in a 20-year-old woman with congenital portal vein atresia is described. Compromise of the underlying esophageal wall due to recent sclerotherapy for bleeding varices predisposed to this highly unusual 'adventitial' variant of the Mallory-Weiss syndrome. Can J Gastroenterol 1989;3(2):58-60
\end{abstract}

Key Words: Esophagus, Variceal hemorrhage

\section{L'hémothorax résultant de la rupture externe des varices esophagiennes: Une complication fatale rare}

RESUME: On rapporte le cas d'une patients de 20 ans, souffrant d'une atrésie congénitale de la veine porte, décédée soudainement à la suite d'une hémorragie survenue dans la cavité pleurale et provoquée par une déchirure linéaire de la paroi externe de l'esophage, après vomissements. Laffaiblissement de la paroi esophagienne sous-jacente due à une sclérothérapie récente pour saignement de varices prédisposait à cette variante particulièrement rare du syndrome de Mallory-Weiss.

Department of Pathology, Ottawa General Hospital and University of Ottawa, Ottawa, Ontario Correspondence and reprints: Dr N.H. Bramwell, Department of Pathology, McMaster University Medical Centre, 120 Main Street West, Hamilton, Ontario L8N 325. Telephone (416) 521-2100 ext 6330 Received for publication December 1, 1988. Accepted December 9, 1988
A 20-YEAR-OLD WOMAN WAS ADMIT ted with hematemesis. The patient had a long medical history, with an episode of hematemesis at the age of 20 months prompting investigations which led to a diagnosis of esophageal varices and portal hypertension due to congenital portal vein atresia. At the age of 10 years the patient underwent a mesenterocaval bypass using a Teflon graft recovery from which was complicated by a subphrenic abscess. Although the graft had never functioned satisfactorily, with occlusion confirmed by venography, the patient had remained well with no further episodes of bleeding until this admission.

The patient's course in hospital was a difficult one. Bleeding was not adequately controlled with a Blakemore tube and intravenous pitressin. A splenic and mesenteric venogram on the second hospital day showed an atretic portal sys- 
tem characterized by a small portal vein extending to the porta hepatis with division into small attenuated venules with no peripheral channels identifiable. Most of the venous return from the superior mesenteric and splenic veins drained via a grossly enlarged coronary vein leading to large gastric and esophageal varices (Figure 1). On the third hospital day a saphenous vein bypass graft between the superior mesenteric vein and the inferior vena cava was performed.

Preoperatively, the patient received 23 units of packed cells, six units of fresh frozen plasma, four units of albumin and $12 \mathrm{~L}$ of crystalloids. An intraoperative hypotensive episode was controlled by ligation of the left gastric vein.
Postoperatively, bleeding persisted. On the eighth hospital day esophagogastroscopic sclerotherapy was attempted unsuccessfully. A venogram at this time showed the graft to be functioning well. Liver function tests, including coagulation factors, were normal throughout the hospital course. Further bleeding was managed conservatively until a massive bleed on the 12 th hospital day necessitated ligation of varices and devascularization of the stomach with a feeding jejunostomy. Recovery was complicated by septicemia secondary to intra-abdominal abscesses (blood cultures grew Staphylococcus aureus and Streptococcus faecalis) leading to wound dehiscence by the 24 th hospital day. Antibiotics were adminis- tered and a further laparotomy for lysis of adhesions, revision of jejunostomy and a secondary wound closure were undertaken. Seven days postoperatively the patient had been extubated and appeared to be progressing well. On the morning of the 39th hospital day a chest $x$-ray was normal. Shortly thereafter the patient had an episode of forceful vomiting, following which she suddenly became obtunded and cyanotic. Resuscitation attempts were unsuccessful.

\section{AUTOPSY RESULTS}

Macroscopic: On opening the thorax, the left pleural cavity was found to contain $1500 \mathrm{~mL}$ of fresh blood with a markedly atelectatic lung. After evisceration,

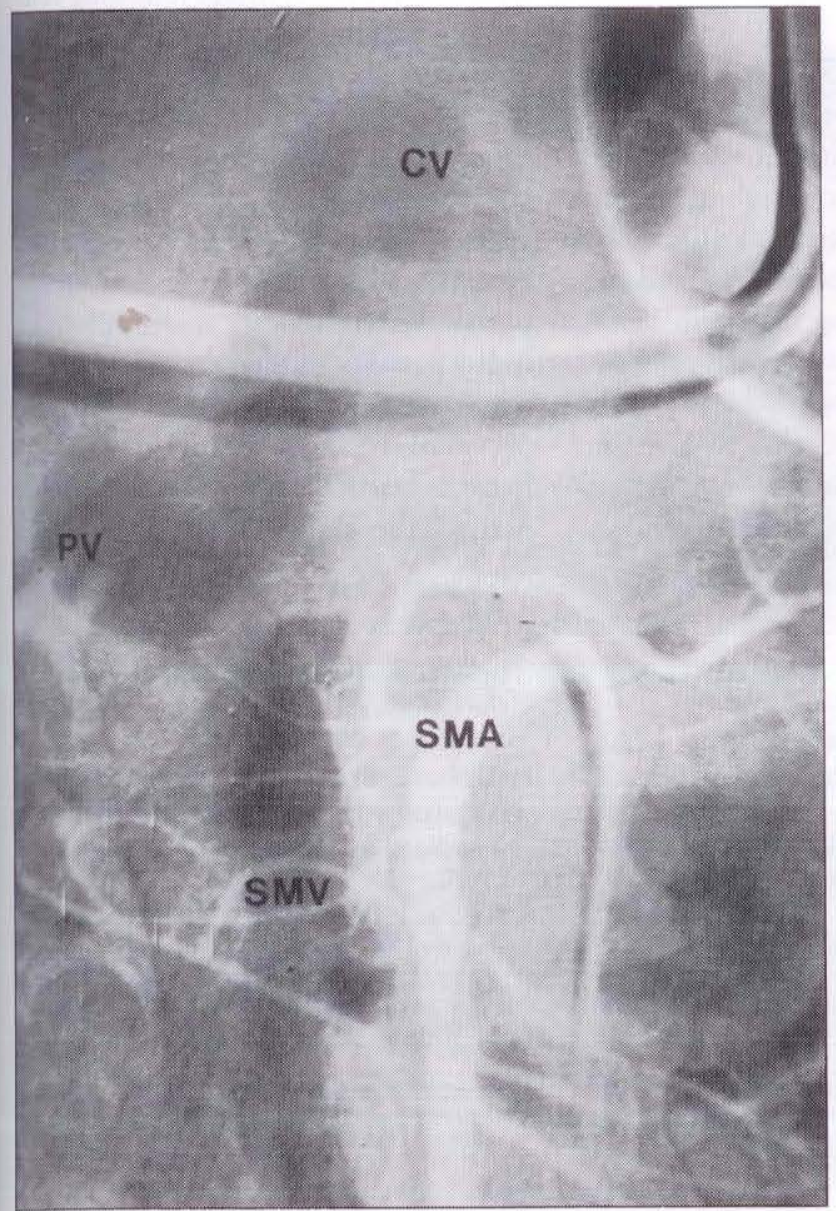

Figure 1) Angiogram of superior mesenteric artery (SMA) in which the distended portal system is visible in the venous phase as areas of deeper lucency. The superior mesenteric vein (SMV) can be traced superiorly into the portal vein (PV) which has a short course and a blunt attenuation in the liver: Drainage is occurring largely via a markedly dilated coronary vin (CV) seen following a tortuous course towards the area of the gastroesophageal junction and the site of the varices which represent tributaries of this vessel

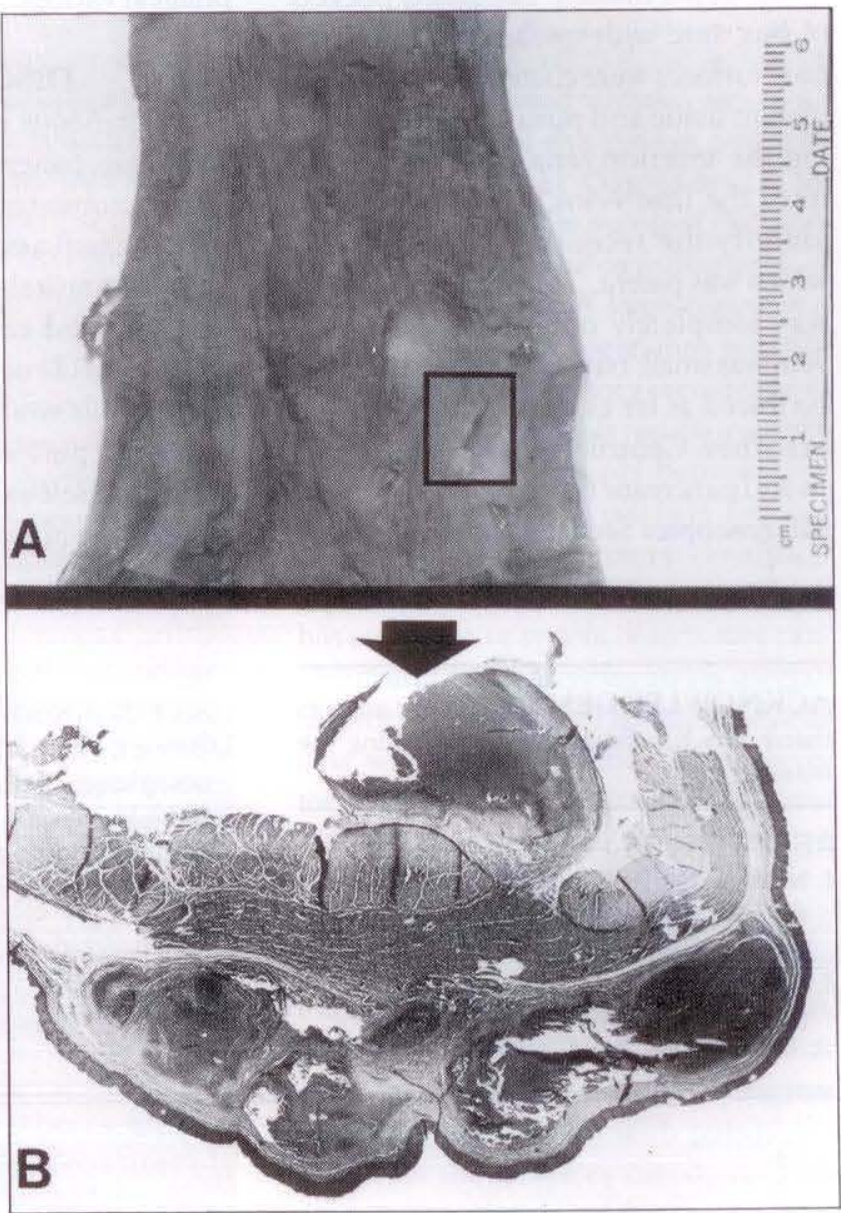

Figure 2) A External surface of the esophagus following fixation and opening with the mucosal surface underneath. The longitudinal tear in the esophageal external surface is visible on its left lateral aspect (within rectangular oulline). B Photomicrograph illustrating a section through the esophageal wall taken at the level of the tear seen grossly in A. External to the muscular coat is a distended adventitial vein, the wall of which is largely necrotic. The site of rupture and hemorrhage is visible (arrow). Hematoxylin and $\operatorname{cosin}(\times 9)$ 
the esophagus, stomach and proximal small bowel were examined separately. Large, prominent varices were easily seen over the distal one-third of the esophagus. The adventitial veins of the esophagus were dilated and tor tuous. On close examination of the external surface of the esophagus, a $1.2 \mathrm{~cm}$ longitudinal tear was encountered which was $5 \mathrm{~cm}$ above the gastroesophageal junction on the left, anteriorly (Figure 2). No mucosal tear, or blood in the esophageal lumen or stomach, was found. The right lung was congested and no evidence of aspiration was encountered in the airways.

The abdomen was easily entered via the recent laparotomy incision. Distended loops of dusky coloured bowel, densely adherent to one another, were found. The adhesions were soft and easily dissected bluntly. Loculated pockets of pus were widespread and all peritoneal surfaces were coated by florid granulation tissue and purulent debris. Tracing the inferior vena cava proximally from the iliac veins, it was possible to identify the recent mesocaval shunt, which was patent. The older Teflon graft was corapletely occluded. The portal vein was small, but identifiable and could be traced as far as its small intrahepatic branches. Centrilobular hepatic necrosis and pancreatic fat necrosis were noted. Microscopic: Sections from the esopha-

ACKNOWLEDGEMENTS: The authors thank Mrs K.J. Bramwell for preparing the manuscript.

\section{REFERENCES}

1. Morritt GN, Walbaum PR. Spontaneous dissection of the oesophagus. Thorax 1980;34:898-900.

2. Mallory GK, Weiss S. Haemorrhages from lacerations of the cardiac orifice of gus revealed extensive necrosis of the muscular coat in the area adjacent to the varices. Dilated venous channels with degenerative mural changes and perivascular hemosiderin deposition were prominent and in one area one such channel communicated with a breach at the muscularis-adventitial interface corresponding to the linear tear seen macroscopically (Figure 2).

Histopathological findings in the liver and pancreas correlated with the gross changes. The remainder of the macroscopic and microscopic examination revealed no significant pathological changes.

Death was attributed to shock and acute cardiorespiratory compromise due to left hemothorax and lung collapse resulting from external rupture of esophageal varices.

\section{DISCUSSION}

Spontaneous perforation of the esophagus in patients without varices is a well documented, if infrequent, condition (1) often associated with unusually high intramural pressures induced by vomiting and retching (Mallory-Weiss syndrome) (2) or even by a suppressed sneeze while swallowing food and air (3). Acquired perforations due to foreign bodies are self explanatory.

Patients with esophageal varices, how-

the stomach due to vomiting. Am J Med

Sci 1929:178:506-15

3. Borrie J, Sheat J. Spontaneous intramural oesophageal perforation. Thorax 1970:25:294-300

4. Anon. Bleeding oesophageal varices. Lancet 1984;i:139-41. (Edit)

5. Graham DY, Smith JL. The course of patients after variceal haemorrhage. Gastroenterology 1981;80:800-9.

6. Natsuda Y, Kuwano H, Ezaki T, et al. ever, usually bleed on the basis of spontaneous rupture of swollen submucosal veins into the lumen in the absence of causative forces such as vomiting $(4,5)$. Such hemorrhages usually, therefore, lie outside the category which embraces the Mallory-Weiss and Boerhaave syndromes (6). This distinction was made endoscopically by Alvarez and co-workers in their study of children with portal obstruction in whom $79 \%$ suffered some form of gastrointestinal hemorrhage, the majority unrelated to a definite precipitating event $(7,8)$.

The present patient represents a highly unusual situation in which therapeutically induced compromise of the structural integrity of the esophageal wall, combined with large adventitial varices. made her vulnerable to external rupture with massive hemorrhage following vomiting. While the Mallory-Weiss phenomenon classically involves the esophageal mucosa, this case demonstrates that increased intraluminal pressure can cause tearing at any level of the esophageal wall, given appropriate predisposing circumstances. The potential seriousness of this rare complication is emphasized by the patient's sudden deterioration and death. This unusual complication, not previously reported to the authors' knowledge, is worthy of note by clinicians who manage these difficult cases.
Spontaneous submucosal dissection of the oesophagus. A case report. Jpn J Surg 1983; 13:354-7.

7. Alvarez F, Bernard O, Brunelle F, et al. Portal obstruction in children. I. Clinical investigation and haemorrhage risk. J Pediatr 1983; 103:696-702.

8. Alvarez F, Bernard O, Brunelle F, et al. Portal obstruction in children. II. Results of portosystemic shunts. J Pediatr 1983;103:703-7. 


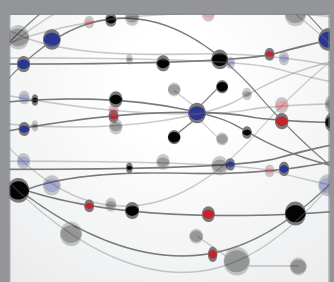

The Scientific World Journal
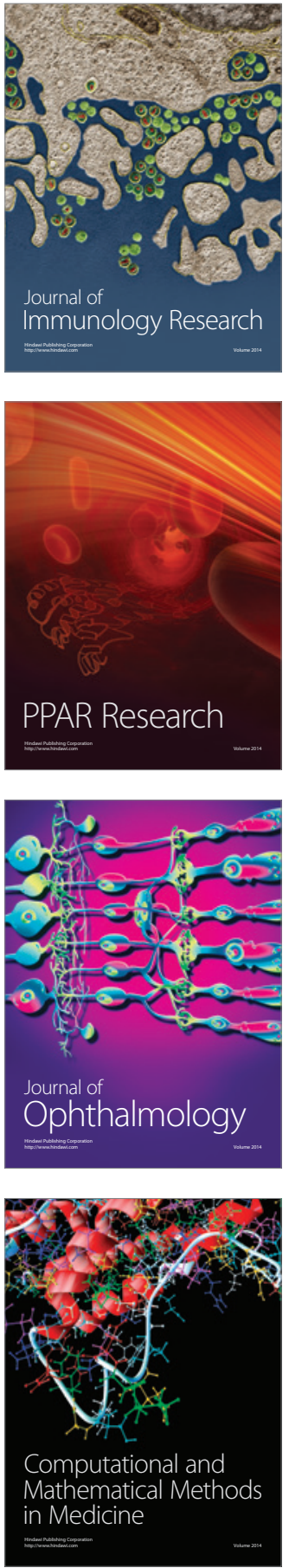

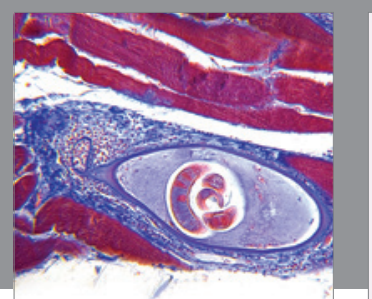

Gastroenterology Research and Practice

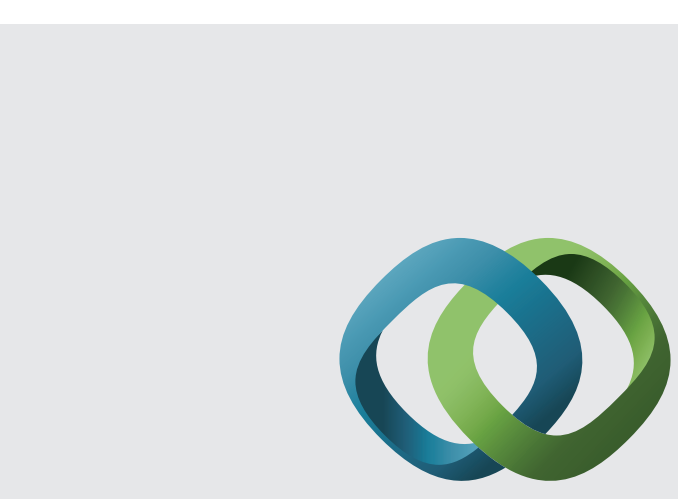

\section{Hindawi}

Submit your manuscripts at

http://www.hindawi.com
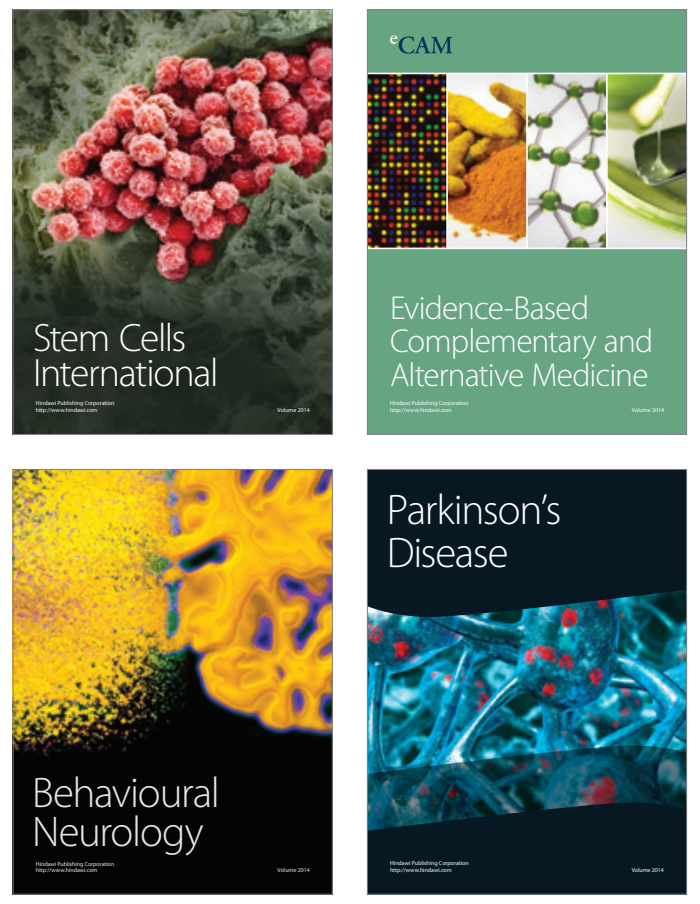
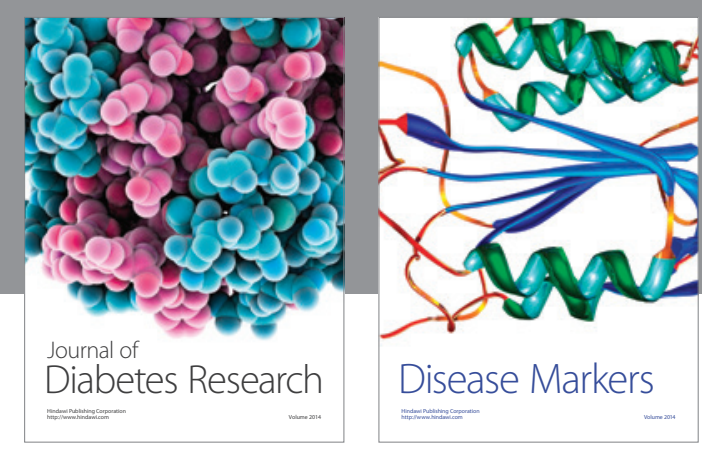

Disease Markers
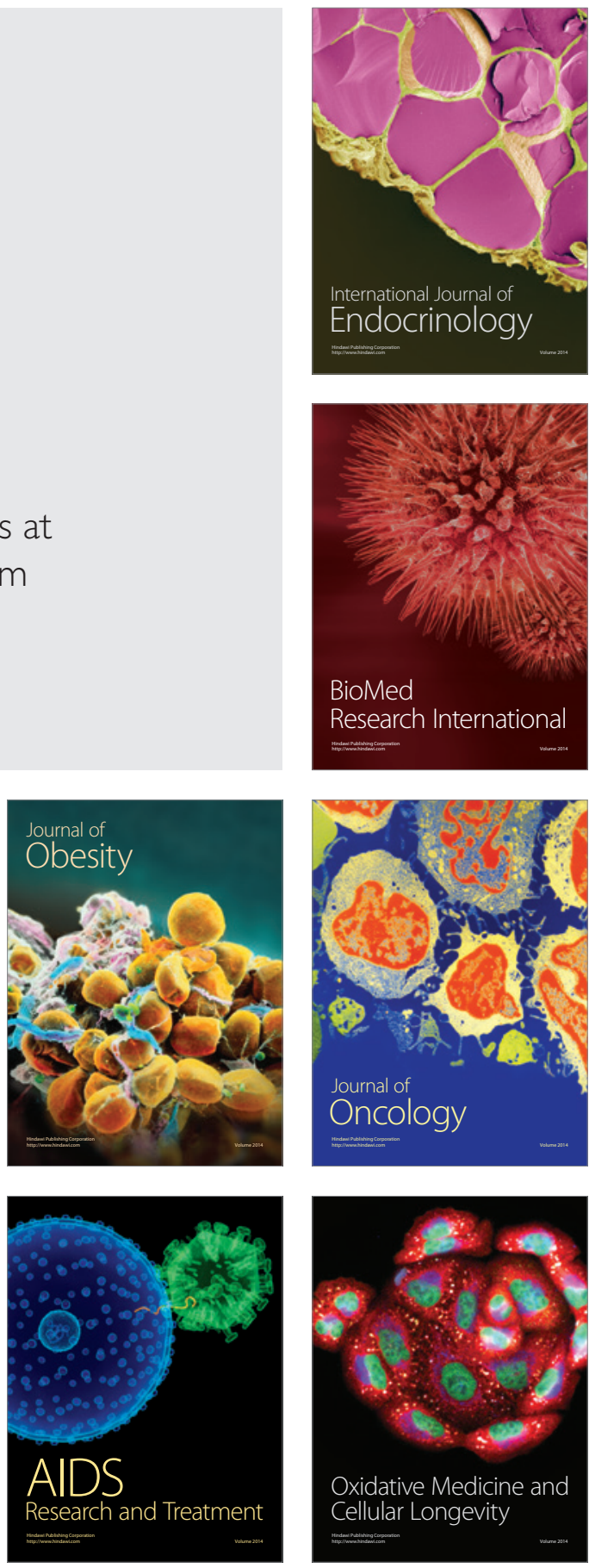